\title{
A dor em movimento: corpo e envelhecimento nas academias de ginástica
}

\author{
Aline Alcarde Balestra
}

\begin{abstract}
resumo Partindo de uma etnografia em academias de ginástica, este artigo propõe uma reflexão sobre as experiências do corpo e do envelhecimento vivenciadas por mulheres que frequentavam as academias etnografadas. $\mathrm{O}$ interesse deste trabalho volta-se para o entendimento e percepção etnográfica da maneira pela qual mulheres, na faixa etária dos 40 anos ou mais, relacionavam-se com o espaço da academia e com as práticas corporais que nele desenvolviam. Procurando um deslocamento da concepção de um sujeito único e humano, são exploradas relaçóes entre gênero, corpo, envelhecimento, dor, doença e movimento. Objetiva-se, assim, tornar perceptível o caráter pragmático e relacional da experiência vivenciada por essas mulheres ao praticarem exercícios físicos e, igualmente, questionar conceitos supostamente estabelecidos como saúde, beleza e bem-estar.
\end{abstract}

palavras-chave Academia de ginástica. Corpo. Ecologia. Envelhecimento. Experiência.

Muitos de meus conhecidos me dizem palavras gentis como: "Impressionante! Como você consegue se manter saudável? Na sua idade!" ou "Você ainda nada? Que maravilha!". Sinto-me um equilibrista, familiarizado com os riscos de seu modo de vida e razoavelmente certo de que alcançará a escada na outra ponta da corda, voltando ao chão tranqüilamente a seu devido tempo.

(Norbert Elias, in Envelhecer e Morrer, 2001, p. 81)

\section{Etnografia, corpos e academias}

O presente artigo propóe uma reflexão a partir de sensaçóes narradas e de experiências compartilhadas entre mulheres que tinham 40 anos ou mais ${ }^{1}$ e frequentavam, com maior ou menor assiduidade, academias de ginástica. $\mathrm{Eu}$, na posição de pesquisadora, compartilhei da prática do exercício físico naqueles contextos; mas, além de meus propósitos serem radicalmente distintos, voltados para a pesquisa etnográfica que desenvolvia, não compartilhava com aquelas mulheres uma experiência específica, a experiência do envelhecimento. Isso não implica dizer que, de modo mais amplo, o envelhecimento não fosse uma experiência comum, visto que nós, de igual maneira, contávamos os anos de vida progressivamente partindo da menor idade, qualificada como mais "jovem", para a maior idade, tida como mais "velha”. ${ }^{2}$ Mas, dada minha convencionalmente atribuída "juventude", o considerado processo de envelhecimento não me interpelava de maneira tão intensa e cotidiana quanto o via entre essas outras mulheres, "mais velhas", frequentadoras das academias de ginástica.

A etnografia da qual trarei elementos para reflexão, foi realizada entre 2006 e 2007 em academias de ginástica localizadas em Agudos e Campinas, cidades do interior do Estado de São Paulo (SP). O trabalho de campo desenvolvido envolveu minha participação como aluna nas academias etnografadas; conversas informais com alunas e alunos, professoras e 
professores, funcionárias e funcionários; entrevistas; análise de documentos produzidos pelas academias; ${ }^{3}$ e a observação direta das práticas realizadas nesses espaços. A pesquisa foi realizada em três academias de ginástica, sendo duas delas localizadas na cidade de Campinas-SP Academia Figueiredo e Fisiomania - e uma na cidade de Agudos-SP - Academia Aqua Fisio. ${ }^{4}$ A Academia Figueiredo era caracterizada por oferecer várias modalidades de exercícios corporais. Por outro lado, tanto a Academia Aqua Fisio quando a Fisiomania ofereciam apenas exercícios realizados em piscinas, como natação e hidroginástica. As conversas, entrevistas e observações realizadas voltaram-se para as práticas e vivências de mulheres na faixa etária dos 40 anos ou mais, buscando explorar em que medida relaçóes entre gênero, corpo e envelhecimento podiam ser pensadas naqueles contextos.

Atualmente, o que podemos observar como um intenso investimento sobre o corpo tem sido relatado e interpretado a partir de estudos realizados em academias de ginástica, tanto brasileiras como estrangeiras (cf. Malysse, 2002; Castro, 2003; Fraga \& Soares, 2003; Vaz, 2003; Frugoli, 2004; Sassatelli, 1999, 2010). Esse investimento pode ser observado, igualmente, em contextos que extrapolam o das contemporâneas academias de ginástica: em conversas cotidianas, propagandas de televisão, embalagens de alimentos, dentre outros.

Sant'Anna (2002) afirmou que o investimento atual (e ocidental) sobre os corpos assume a forma de um controle-estímulo, como havia sugerido Foucault ([1976] 1988). Dessa maneira, o corpo não seria mais reprimido, mas estimulado a ser cada vez mais saudável, jovem e fonte de prazeres. Tais exigências acabariam por provocar uma vontade incessante de proteger e adular o corpo (cuidados antes dirigidos à alma), o que significaria uma melhor maneira de cuidar de si, de afirmar a própria personalidade e ser feliz. Goldenberg \& Ramos (2002) observaram o surgimento de uma nova moralidade ocidental, não mais aquela em que o certo se assenta sobre o ato de manter os corpos escondidos: o corpo, particularmente no contexto carioca, deve ser descoberto, mostrado. Essa atitude, porém, não é tão livre quanto possa, a princípio, parecer: ela está pautada por um conjunto de regras que especificam a aparência do corpo moralmente aceito.

Goldenberg \& Ramos (ibidem) relacionaram a nova "moral estética" com a ocorrência de transformaçóes históricas e culturais, tais como o enfraquecimento de instituiçóes que tradicionalmente produziam identidades: a família, a religião, a política, o trabalho etc. Consequentemente, os indivíduos na atualidade passariam a se utilizar de seus corpos para expressar o "eu". Refletindo um processo de individualização, a pessoa apareceria como o maior responsável tanto pela sua aparência física como pela sua saúde, sendo cada indivíduo considerado responsável e culpado por sua juventude, beleza e saúde. Por meio dessa perspectiva, só é feio aquele que quer, e envelhece quem não se cuida, cada um devendo "buscar em si as imperfeições que podem (e devem!) ser corrigidas" (id., ibidem, p. 9). O corpo, nesse sentido, passaria a ser percebido como matéria plástica, ou seja, um material capaz de ser construído e reconstruído incessantemente, tendo como ponto de partida a simples vontade pessoal.

A prática que hoje denominamos "ginástica" delineou-se, de forma mais clara, no início do século XIX, em um contexto europeu. Esta, em oposição às práticas corporais tradicionais da época, separava-se das atividades da vida ordinária (trabalho) e extraordinária (jogo, competição e diversão); seus exercícios físicos obedeciam a um ritmo próprio, rompendo com 
A DOR EM MOVIMENTO: CORPo E ENVELHECIMENTO NAS ACADEMIAS DE GINÁSTICA $\mid 67$

o tempo social da vida camponesa, militar e das cortes. A ginástica, naquele momento, passou a ser caracterizada por competiçóes permanentes e abertas a qualquer indivíduo, não apenas aos heróis ou aos mais fortes (Mira, 2004). Atualmente, as academias de ginástica apresentam-se como locais que possuem suas próprias regras, vocabulário, vestimentas, usos do corpo, organização do tempo e do espaço. Esta cuidadosa organização tempo-espacial está relacionada à criação de um meio onde é possível se concentrar no treino corporal ali empregado e se esquecer, de certa maneira, de outras questóes relacionadas à vida cotidiana (Sassatelli, 1999). As práticas ali desenvolvidas se caracterizam, sobretudo, pela imensa diversidade de exercícios corporais, sendo colocada uma ênfase nas variadas possibilidades de treino corporal, as quais podem contemplar gostos igualmente diversificados. As academias proporcionam, assim, condiçôes específicas para o uso do corpo e para a concentração no movimento corporal, podendo ser entendidas como um espaço que tem suas próprias regras, proporcionando vivências e experiências específicas.

Como, então, podemos perceber tais experiências e vivências relacionadas ao uso do corpo neste espaço-tempo específico? O que acontece quando entramos na academia de ginástica, local, por excelência, onde esse corpo é produzido (id., ibidem, p. 227-228)? Como é vivenciado, tomando como verdadeiro, este estímulo de buscar um corpo cada vez mais saudável, jovem e fonte de prazeres? Uma das perguntas centrais de minha pesquisa referia-se justamente a este ato de ocupar a academia e de realizar, em seu contexto, um uso específico do corpo. De um modo geral, a literatura sobre o assunto apontava as mulheres como principais vítimas de uma ditadura moral do corpo e da estética. Mas, afinal, de que corpo se tratava? Essas mulheres estavam, de fato, à procura de um corpo exatamente conforme os moldes divulgados pela moral estética vigente? De algum modo o fato de "malharem" seus corpos estava relacionado com a experiência de se constituírem enquanto "mulheres" de certa idade?

Minha experiência etnográfica não me conduzia à percepçáo de que o espaço-tempo da academia fosse um no qual imperasse o sofrimento e a busca desmedida por um corpo magro, esbelto e livre das gorduras. Não me parecia também que o corpo era um objeto inerte e passivo sobre o qual o sujeito imprimia seus objetivos previamente programados com vistas a transformá-lo em um determinado sentido. De fato, muitas mulheres comentavam nem sempre ser fácil acordar cedo e com disposição para ir à aula de ginástica. Outras se remetiam aos comentários de seus maridos sobre seus corpos como estímulos para a prática do exercício corporal. Mesmo Fernanda (53 anos), ${ }^{5}$ uma frequentadora assídua das aulas de ginástica da academia Saúde \& Movimento e enfática ao afirmar que gostava muito de "malhar", dizia que, para ir sempre à academia, era necessário adquirir o "hábito". Entretanto, o que se podia perceber de maneira muito marcada era o prazer que essas mulheres demonstravam ao estar naquele espaço-tempo da academia. Era notável a animação com que muitas realizavam as aulas ou mesmo a satisfação que demonstravam de estar na companhia de suas colegas de aula. Marta (52 anos, Academia Aqua Fisio), por exemplo, via a aula de hidroginástica como local em que conversava com suas colegas, o que a distraía de sua vida rotineira. Ela se sentia bem recebida naquela academia que frequentava. Também Sueli (47 anos, Academia Figueiredo) afirmava que as aulas de ginástica traziam a ela "bem-estar", "pique" e "bom humor", o que auxiliava muito seu "intelecto". Ela me relatou, inclusive, que a dor que sentia durante o treino não era uma dor ruim, mas uma "dor 
boa”, uma dor que trazia a ela boas sensaçóes corporais.

Desse modo, a aproximação ao universo das academias e de suas frequentadoras - as quais se colocavam como questão um corpo que envelhecia - permitia contestar uma visão teleológica, segundo a qual mulheres que vão à academia possuem o objetivo específico de adequarem seus corpos aos padróes de estética, beleza e saúde estabelecidos. Contrariamente, tornava-se patente a necessidade de ampliar este escopo de possibilidades, pois o que a etnografia tornava perceptível era distante da existência única de um corpo feminino pré-estabelecido o qual se buscava: muito parecia ser transformado e experimentado naquelas aulas.

Os ensinamentos de Dom Juan e de Castaneda (1969) são inspiradores nesse sentido, pois nos auxiliam a atentar, ampliando nossas percepções, para outras formas de sentir e, igualmente, de conhecer. Seus diálogos nos conduzem a uma atividade de conhecimento relacional e pragmática, a qual passa pela experiência de sentir. Em The Teachings of Don Juan: A Yaqui Way of Knowledge, Castaneda relata seus diálogos com Dom Juan, um índio yaqui, feiticeiro e conhecedor dos usos de plantas medicinais e alucinógenas. Uma dessas plantas era o peiote, sobre a qual Castaneda desejava aprender. Aceitando o pedido de ensinar-lhe, Dom Juan estabeleceu uma tarefa inicial: o desafio de encontrar um ponto naquele chão da varanda onde estavam sentados, lugar em que Castaneda sentar-se-ia sem se cansar e se sentiria naturalmente feliz e forte. $\mathrm{O}$ aprendiz, encarando o desafio, passou horas andando, sentando ou rolando pelos variados pontos da varanda na procura de sentir diferenças entre eles. Tal atividade fez com que ele sentisse diferenciaçóes entre quente e frio; mas, ainda assim, não tinha sido suficiente para que encontrasse seu ponto. Decorridas seis horas, Dom Juan apareceu e, confrontando-se com a quase desistência de Castaneda, explicou-lhe que suas açóes haviam sido incorretas, pois não utilizara os olhos em sua busca. Frente a essa constatação, Castaneda admitiu não ter se valido de sua visão, e, certo que estava de que Dom Juan lhe pedira para sentir a diferença entre os pontos, ele não compreendia como poderia fazê-lo com os olhos. Frente ao argumento de Castaneda, Dom Juan esclareceu-lhe que se pode sentir com os olhos quando estes não estão voltados diretamente para dentro das coisas. Acrescentou ainda que, se fosse ele a realizar aquela busca, não teria pensado em outra maneira de resolver o enigma a não ser por meio desta técnica.

A proposta inusitada de sentir com os olhos que Dom Juan dirige a Castaneda - algo em que este não teria pensado na empreitada de conhecimento de seu ponto de felicidade e fortaleza - pode nos conduzir a dois movimentos no que se refere à atividade de conhecer. Primeiramente, tal proposta torna possível conceber uma atividade de conhecimento que se relaciona com o ambiente ao seu redor. Permitindo-se sentir com os olhos, Castaneda foi capaz de perceber outros elementos que não havia notado anteriormente, como o chão, os pontos e as cores presentes no ambiente. Estes também se constituíram enquanto entidades atuantes ${ }^{6}$ em sua busca, indicando-lhe o caminho para a descoberta de seu ponto. Em segundo lugar, essa forma de conhecimento torna-se ainda mais interessante quando observamos que ela passa especificamente pela experiência de sentir por meio de um corpo que se movimenta pela varanda da casa de Dom Juan. Desse modo, o ato de conhecimento de Castaneda deve ser tomado como inspiração para os propósitos deste artigo, pois apenas pela percepção de um ambiente ampliado e de um corpo que não está dado ou circunscrito é que se torna possível perceber como a experiência das mulheres nas 
A DOR EM MOVIMENTO: CORPo E ENVELHECIMENTO NAS ACADEMIAS DE GINÁSTICA 69

academias também não estava dada por princípio, mas possibilitava a elas um novo modo de vivenciar seus corpos e mesmo de criá-los. Nesse contexto, corpo e gênero não poderiam ser encarados como conceitos estáveis, mas eram ativamente reinventados naquela experiência.

\section{Entre beleza e saúde?}

Ana Lúcia de Castro (2003), a partir de uma pesquisa realizada em academias de ginástica da cidade de São Paulo, com um público de variadas idades e classes sociais, observou uma recusa por parte das pessoas entrevistadas em declarar a preocupação estética como principal motivação para a prática regular de exercícios físicos. A saúde foi assumida com orgulho por essas pessoas como a principal motivação para a prática da atividade física. Para a autora, tal recusa poderia estar ligada ao resíduo latente de um ethos que confere futilidade à preocupação com aspectos exteriores, sendo a imagem corporal um desses aspectos. $\mathrm{Na}$ verdade, a principal motivação para a prática de exercícios físicos seria a busca do embelezamento, embora não declarada. Desse modo, o "culto ao corpo" foi definido pela autora como "um tipo de relação dos indivíduos com seus corpos que tem como preocupação básica o seu modelamento, a fim de aproximá-lo o máximo possível do padrão de beleza estabelecido" (id., ibidem, p. 15).

No mesmo sentido, Fernandes (2004) argumentou que a ginástica se configura como uma possibilidade de modificação corporal em busca do padrão de beleza e de boa forma, a saúde aparecendo como um objetivo apenas no nível do discurso, opondo-se à prática. Fernandes observou, também, uma equivalência entre termos como "bem-estar", "saúde", "qualidade de vida" e "alimentação". Termos esses que, para ela, não poderiam ser confundidos, uma vez que restringem o conceito de saúde à esfera de responsabilidades individuais e aspectos circunscritos ao indivíduo, como o bem-estar e a estética corporal.

Logo no início do trabalho de campo, pude igualmente perceber que noçóes tais quais "bem-estar", "beleza" e "saúde" acabavam por aparecer simultaneamente nas falas das mulheres, apontando, em determinadas circunstâncias, uma não distinção entre tais fronteiras conceituais. De fato, em um primeiro momento, quando eu colocava a questão "Por que você frequenta a academia?", era raro ouvir uma resposta direta que afirmasse estarem os motivos relacionados à busca de um corpo mais belo. Entretanto, para além da entrevista formal, ao estar em campo, partilhando conversas e aulas, pude observar que saúde e beleza não estavam colocadas enquanto totalidade e que outros termos e sensaçóes eram apresentados pelas mulheres. Além do mais conhecido "bem -estar", era possível se ouvir muitos "sentir-se bem”, "boa sensaçâo”, "disposiçãa”, "bom humor", "pique”, "sentir-se alegre”, "sentir-se viva", "estar mais desperta", "qualidade de vida" e "vitalidade".

A observação de tal indistinção entre saúde e beleza extrapola o contexto das academias de ginástica. Nikolas Rose (2001), discutindo as biopolíticas aplicadas a contextos ocidentais na segunda metade do século XX, nota mudanças ocorridas na interpretação do conceito de saúde. Da preocupação restrita à ocorrência de doenças e mortes prematuras, o conceito se estende: o ser humano saudável é aquele que, além de não estar doente, é belo, tem sucesso, felicidade e uma vida sexual satisfatória. De maneira semelhante, a existência, na atualidade, de cosméticos com função terapêutica e alimentos-cosméticos (por exemplo, iogurtes 
anti-rugas) sugere igualmente o apagamento das fronteiras entre beleza, saúde e bem-estar (Sant'Anna, 2002).

Essa indefinição conceitual coloca-nos questôes que não podem ser pensadas em termos de motivaçóes para se frequentar academias de ginástica. Dizer que as mulheres com as quais me relacionei nas academias de ginástica, na verdade, mentiam quando afirmavam ir à academia por estarem interessadas em cuidar de sua saúde ${ }^{7}$ seria limitar a questão e não levar a sério (Viveiros de Castro, 2002; Stengers, 2008) o que elas me diziam. Seria, igualmente, sustentar um dualismo e uma diferença entre discursos e práticas que pautavam a ida à academia, contrapondo a motivação relacionada à saúde nos discursos à motivação relacionada à beleza nas práticas.

As dificuldades resultantes dessa oposição não são novas na antropologia. Malinowski ([1916] 1988) confrontou-se com o desafio de lidar com a grande variedade de opinióes dos nativos quando, em sua formação, havia sido educado a imaginar totalidades homogêneas e isoladas, à espera do olhar abarcador e hábil a generalizaçóes significativas, próprio ao antropólogo bem treinado. Diante desse imprevisto, para ter o alcance do que considerou uma crença nativa em sua completude, julgou fundamental analisar toda a sua dimensão social, a qual abarcava, em seu entendimento, não apenas as interpretaçóes dos nativos, mas suas instituiçõos sociais e comportamentos. Malinowski diferenciava, assim, opinióes de comportamentos e buscava ampliar seu escopo de observação (toda a dimensão social) a fim de superar as possíveis contradiçôes entre essas duas dimensões. Podemos, também, com Peirano (2002), lembrar-nos da distinção entre mitos e rituais, muito presente nos estudos antropológicos, a qual, em diversos momentos, conduziu à problemática dicotomia entre rela- ções sociais (ou realidade) e representações.

Pensar as diferenças entre discursos e práticas em termos de "mentiras" (ou falas politicamente corretas) e "verdades" não nos retira, portanto, do solo moderno em que "os outros", de uma maneira ou de outra, são definidos por suas crenças, enquanto "nós" somos aqueles que temos a possibilidade de ver as coisas como elas realmente são graças a nossos olhos que não se deixam iludir (Pignarre \& Stengers, [2005] 2007, p. 88). Por outro lado, a atitude de levar a sério como proposta por Viveiros de Castro (2002) e Stengers (2008) diferencia-se da atitude de acreditar. Não se trata de encarar o pensamento alheio como uma opinião, um objeto passível de crença ou descrença, mesmo porque a questão da verdade não se coloca nesses termos. Não se trata, igualmente, de reafirmar a grande divisão do território moderno: eles acreditam, nós sabemos. Nesse sentido, descobrir o que motivava as mulheres a trabalharem o corpo nas academias por detrás do que elas me diziam seria supor, em mim, uma capacidade e um conhecimento que superasse os possíveis entendimentos e esclarecimentos que aquelas mulheres tinham sobre suas práticas naquele espaço. Proponho-me, contrariamente, a pensar que não seria esta a suposição a seguir ou relação a estabelecer. Com tal intenção, este texto busca se constituir como um exercício de pensar em nossos conhecimentos - os meus e os das mulheres com mais de 40 anos que frequentavam as academias de ginástica - como diferentes, sendo a relação possível entre eles não traduzível em um desvelamento, revelação ou explicação.

Um primeiro passo nessa direção envolve um deslocamento de questôes, passando de perguntas que antecediam o trabalho de campo e, consequentemente, as relaçôes que ele possibilitava, para a percepção de questóes trazidas naquele contexto. Envolve, portanto, um olhar 
A DOR EM MOVIMENTO: CORPo E ENVELHECIMENTO NAS ACADEMIAS DE GINÁSTICA $\mid 7$ I

que se dirija não aos motivos relacionados à prática constante de exercícios físicos, mas ao modo pelo qual aquelas mulheres iam à academia, buscando perceber como elas estavam lá, o que estava envolvido em suas açóes naquele espaço específico e quais relaçóes estabeleciam com o ambiente ao seu redor. Nesse sentido, levar a sério o que essas mulheres me diziam ${ }^{8}$ conduz-me a fazer uma reflexão não sobre representaçóes do próprio corpo, mas sobre a experiência do corpo (Merleau-Ponty, [1945] 1996) e as relaçóes entre tal experiência e outras, que extrapolam o contexto específico da academia. Faz-se necessário um deslocamento da concepção de um ser pensado a partir de uma forma mais abstrata, como aquele que dá sentido ao mundo, para um ser-no-mundo, o qual passa necessariamente por experiências que se fazem sentir no corpo. Assim, este artigo se propóe ao deslocamento de um sujeito único e humano para uma percepção que busque a ampliação dos agentes envolvidos nas práticas corporais desenvolvidas.

\section{O uso do corpo}

Na maioria de suas aulas, Sérgio, professor de ginástica, apresentava às alunas e alunos ${ }^{9}$ duas ou três posiçóes e formas possíveis de se realizar um determinado movimento: com ou sem o step, ${ }^{10}$ usando ou não os braços, nesta ou naquela posição. Apenas não era facultativo o uso do corpo, e isto ele fazia questão de frisar. "O corpo", dizia ele, "todo mundo tem que usar!" (Academia Figueiredo). As aulas de Sérgio, fossem elas de "condicionamento físico", "extreme 55" ou "power mix", ${ }^{11}$ eram repletas de frases de incentivo ao trabalho do corpo, tais como: "está doendo...? Então, está bom, porque é pra doer mesmo"; "sofrimento não é nada, imagem é tudo"; ou ainda "I will survive". Apesar da ironia das mesmas - uma vez que remetiam ao sofrimento e à dor - suas frases pareciam, de fato, motivar as aulas, incentivando o uso do corpo, uso que ele colocava como imprescindível. Era notável o ânimo das alunas e alunos, logo às 7 h30 da manhã, e o apreço demonstrado pelo professor.

Sandra (50 anos) frequentava aquela academia havia seis meses, mas não as aulas de Sérgio: ela gostava de musculaçáo. Como me contou, era a primeira vez que praticava esta modalidade de uso corporal, mas já notava que o treino trazia um "bom resultado": ela "sentia a diferença”. Antes, morando em Santos-SP, Sandra corria durante as manhãs, caminhava ou andava de bicicleta. Ela considerava a Academia Figueiredo de boa qualidade, pois contava com aparelhos variados e com um professor de musculação bastante dedicado. O preço não havia sido um fator de escolha: frequentava a academia porque "gostava mesmo" e, depois, pela "vaidade", mesmo porque já tinha "uma certa idade". Segundo ela, quando se começa a ficar mais velha, "tudo caî", sendo uma "necessidade" a prática de exercícios. Sandra considerava diferente o envelhecimento da época de sua mãe e de seus avós para os dias de hoje, porque, nos tempos atuais, pensa-se mais em qualidade de vida e há um desejo maior de se conquistar uma boa saúde. Ela citou seu exemplo: era fumante, bebia e agora tinha "parado tudo" em busca de "uma vida melhor", com "mais disposição". Ainda assim, envelhecer era "ruim", pois se tratava de um processo que acabava por deixar a mulher deprimida: Sandra se sentia, às vezes, "meio pra baixo". Isso acontecia, segundo ela, porque seu corpo não acompanhava sua mente: aquele envelhecia enquanto esta permanecia jovem. O problema do envelhecimento do corpo não era, entretanto, relacionado à sua aparência - esta poderia ser facilmente resolvi- 
da com uma plástica, por exemplo, desde que se tivesse dinheiro para isso -, mas à sua "disposição”, pois o corpo mais velho já não tinha o mesmo "pique" de um corpo novo. Como ressaltou Sandra, o problema era o "limite" estabelecido, razão pela qual não se podia deixar de frequentar a academia, caso contrário, "a situação ficaria pior ainda”. Sandra já não tinha o mesmo ânimo para "enfrentar uma noitada" e reparou que o mesmo acontecia com seus amigos, fossem eles homens ou mulheres. Este processo era, entretanto, inevitável: "todo mundo tinha que passar pelo envelhecimento".

Já Vera, que tinha 69 anos e era frequentadora de outra academia da cidade de Campinas, a academia Fisiomania, praticava aulas de hidroginástica havia 4 anos e começara a fazer exercícios físicos por recomendação médica. Vera afirmava, de forma descontraída, que tinha um "problema de juntas", de "junta tudo e joga fora", e acreditava que as mulheres com mais de quarenta anos frequentavam a academia por motivos de saúde. Ela própria teria que passar por uma cirurgia, mas o médico lhe dissera para tentar resolver seu problema com a hidroginástica, e tinha dado certo, pois a praticava há quatro anos - o que, certamente, era "melhor do que pegar uma cirurgia". Quando lhe perguntei qual tipo de sensação a ginástica lhe trazia, Vera respondeu, empolgadamente, que lhe dava "alegria". Dentro de casa, ficava se lembrando de coisas tristes, mas ir à academia fazia bem para a sua "idade", sua mente era outra. Ela, por exemplo, tinha quase 70 anos e não ia ficar em sua casa fazendo crochê, "de jeito nenhum", porque correria o risco de "pegar uma depressão" - em sua opinião, muita gente tinha depressão porque não saía de dentro de casa, sendo fundamental conviver com as outras pessoas. Vera também me falou sobre o que podemos entender como outras boas ações no âmbito desta sua máxima de que, ao se chegar a certa idade, tem-se que conviver com outras pessoas. Ela, por exemplo, frequentava a "terceira idade", onde jogava bingo - era "bingueira" - e gostava muito de ir à igreja, sendo católica. Por participar da pastoral da saúde, ajudava no hospital e, quando saía de lá, sentia-se muito bem, pois pensava no quanto era feliz ao se comparar com as pessoas que permaneciam naquele lugar. "Quando apertava muito" ia ao médico, mas acreditava que a saúde "é mais da cabeça", porque "ao se procurar muito, acha-se”. Ainda assim, considerava fundamental manter uma alimentação adequada: ela mesma havia feito um exame por aqueles dias e descobrira estar "a um passinho da diabetes".

Percebemos, desse modo, como os relatos de Sandra e Vera ressaltam, dentre outros aspectos, o caráter pragmático e ameaçador $\mathrm{da}$ doença, das dores, de um corpo sem disposição e no limite, ainda que não dito expressamente, da morte. Vera nos fala sobre os riscos que vêm junto com a idade e ressalta o perigo: não é bom procurar muito, pois se pode achar; pode-se estar "a um passinho da diabetes" ou "pegar uma depressão”. Por sua vez, Sandra relata seus medos em relação à ameaça ocasionada pela "idade", a qual traz consigo perdas referentes às partes do corpo que "caem", à sua disposição e também à possibilidade de uma depressão. Notamos, portanto, que as sensaçóes no corpo relatadas por essas mulheres encontram relações que são estabelecidas com outros agentes que extrapolam o contexto específico das academias de ginástica e que estão associados a experiências específicas. Nesse sentido, podemos pensar o uso do corpo experimentado por Vera relacionado às suas experiências com médicos, à possibilidade de uma cirurgia ou de outras doenças, as quais, pragmaticamente, poderiam se fazer sentir em seu corpo.

Maria (58 anos), também frequentadora da academia Fisiomania, compartilhava esse 
A DOR EM MOVIMENTO: CORPo E ENVELHECIMENTO NAS ACADEMIAS DE GINÁSTICA $\mid 73$

entendimento de Vera. Ela se valia do bordado como forma de desligamento e distração de algo "muito triste" que lhe havia acontecido: a perda de um filho de 29 anos. Lidar com esse acontecimento era muito difícil para ela, ainda mais porque seu marido não se conformava de modo algum. E, ainda nos dias em que ela estava melhor, ele a "empurrava para baixo" porque ficava falando sobre esse assunto. $\mathrm{O}$ fato de seu marido ter mais dificuldades para lidar com a perda do filho estava relacionado, segundo Maria, à sua atitude de permanecer o dia todo dentro de casa. Nesse sentido, Maria considerava muito importante sair de casa, não podendo se valer apenas do bordado como atividade de enfrentamento àquele sentimento de tristeza (o bordado, por si só, não era uma medida eficaz). Para Maria, ir à academia certamente não se enquadrava em uma busca isolada por um corpo feminino tal qual o exigido pela dita moral estética vigente. Não que Maria ignorasse um padrão corporal que constantemente lhe fosse informado, pois, segundo ela, o envelhecimento também trazia consigo marcas de expressão facial que o exercício físico ajudava a reduzir. Mas, no ato de movimentar seu corpo, ela descobria novas formas de o sentir, inclusive na companhia de outras mulheres que enfrentavam questôes semelhantes às suas. A prática da hidroginástica a ajudava, por exemplo, a fazer alguns movimentos cotidianos sem sentir dor, como o de abaixar ou o de segurar alguns objetos.

Sandra, Vera e Maria realizavam práticas experimentais específicas que extrapolavam o ato de se enquadrar em um padrão estético pré-estabelecido. Vozes como a do professor Sérgio - "sofrimento não é nada, imagem é tudo" - podiam ecoar, mas suas experiências subvertiam um sentido teleológico único de conquista de um corpo belo e saudável nos termos de um imperativo social. Como bem colocado por Stengers (2008, p. 53), a dimensão subjetiva da experiência, aquilo que é conhecido, sentido e experimentado apresenta, sobretudo, um caráter especulativo, o qual adiciona dimensões às situaçôes. Stengers, ao se referir à subjetividade, não a encara a partir de um modelo dualista, como algo contraposto à objetividade. ${ }^{12}$ Seu entendimento sobre este tema se refere antes a uma "produção de subjetividade", quando algo que foi silenciado e desprezado encontra sua própria voz, produz sua própria opiniāo, seus próprios meios de resistir a consensos morais ou ainda estabelece o que deve ser levado em consideração. Trata-se de considerar posições que são, sobretudo, políticas e que provocam rupturas com consensos genéricos que lhes são exteriores.

Apesar da existência de constrangimentos que estavam associados à necessidade relatada de se fazer exercícios e de se movimentar constantemente - a qual podemos relacionar também a um sentimento de responsabilidade individual sobre o próprio corpo e a velhice (Debert, 2004) -, a academia abria espaço para outras formas de sociabilidade, de movimentos e sensaçóes. As ações desenvolvidas por essas mulheres eram também criativas: nas academias, elas descobriam novas formas de habitar o mundo e de constituir seus corpos. Fugindo às divisóes de gênero e de corpo como esferas constituídas e estanques de análise, podemos perceber como elas estavam nas academias fazendo muito mais coisas do que se constituindo enquanto mulheres, segundo uma categoria imutável e totalmente predefinida. Podemos também pensar seus corpos e experiências a partir da imagem do ciborgue proposta por Donna Haraway (2000): eles não estão comprometidos com a unidade original nem com uma identificação com a natureza, no sentido "ocidental" do termo. O ciborgue é concebido pela autora como uma imagem que questiona, de diversos modos, a totalidade, a unidade e a natureza. Em suas palavras, os ciborgues: 
[...] são as pessoas que recusam desaparecer quando instados, não importa quantas vezes um escritor "ocidental" faça comentários sobre o triste desaparecimento de um outro grupo orgânico, primitivo, efetuado pela tecnologia "ocidental", pela escrita. Esses ciborgues da vida real (por exemplo, as mulheres trabalhadoras de uma aldeia do sudeste asiático, nas empresas eletrônicas japonesas e estadunidenses descritas por Aihwa Ong) estão ativamente reescrevendo os textos de seus corpos e sociedades. A sobrevivência é o que está em questão nesse jogo de leituras (id., ibidem, p. 99).

Trata-se de uma imagem que "pode sugerir uma forma de saída do labirinto dos dualismos por meio dos quais temos explicado nossos corpos e nossos instrumentos para nós mesmas" (id., ibidem, p. 108). Dualismos como corpo/ mente, cultura/natureza, ativo/passivo e também beleza/saúde operam como um modo de limitar as possibilidades criativas e ativas de construção de corpos. A imagem do ciborgue sugerida por Haraway tem o potencial de nos remeter a construções que não são puras, mas um misto de experiências diversas, de junçóes de coisas aparentemente desconexas. Esse potencial pode ser aproveitado para se pensar nas mulheres nas academias, pois elas dotavam termos como "movimento", "dor", "doença", "beleza" e "saúde" de um significado próprio, diretamente associado aos seus modos de habitar o mundo e às questóes que este lhes colocava. A própria dor do exercício físico, como veremos adiante, podia ser encarada como uma experiência dotada de um significado peculiar. ${ }^{13}$

\section{A dor em movimento}

Paula (50 anos), colega de turma de Vera, durante uma aula de hidroginástica, disse-me que fazia caminhadas, mas que estas eram voltadas apenas para o exercício das pernas. Com as aulas de hidroginástica, ela tinha outro objetivo: queria exercitar o corpo todo e se "movimentar mais" para que fossem evitadas dores, pois ela estava sentindo, vez ou outra, torcicolos. O "movimento" era encarado por Paula como um importante agente em sua luta contra as dores que se faziam sentir em seu corpo. Assim como o movimento, outros agentes também podiam ser notados no contexto das academias de ginástica, como o alimento, a idade, a dor e a doença ${ }^{14}$. A percepção dessas “outras" entidades atuantes é possível quando nos deslocamos da concepção de um sujeito auto-centrado e único possuidor da prerrogativa da ação sobre o mundo, assumindo a agência e a afetação que não passam apenas por tal sujeito, mas pelo que Stengers (2008) considerou o seu meio ("milieu”). Leva-nos, desse modo, à abertura a uma ecologia (id., ibidem) e multiplicidade de dimensóes a qual considera o ambiente em um sentido lato, sobretudo no que se refere à percepção da presença ativa de variados entes.

Nessa perspectiva, o "movimento constante" e uma "boa alimentação" podem ser percebidos como poderosas armas contra a dor e as doenças, as quais pareciam ser tão inevitáveis no chamado e vivido processo de envelhecimento. As dores agiam como limitaçóes à realização de tarefas cotidianas, como limpar a casa, ${ }^{15}$ e $a$ idade trazia consigo uma falta de disposição para programas que exigissem mais energia, como sair com amigos e amigas, conforme colocado por Sandra. Por outro lado, estavam também presentes sentimentos de tristeza e depressão: muitas mulheres relataram estar tomando ou terem tomado antidepressivos. O processo de envelhecimento estava relacionado a uma desaceleração do corpo, a uma sensação de perda de “disposição", "pique” e "ânimo”. Sandra falava 
sobre um "limite" que se estabelecia e se fazia sentir em seu corpo, e ressaltava que, frente à inevitabilidade do processo de envelhecimento ("todo mundo tem que passar por isso"), não era possível "parar com a academia", caso contrário, a situação acabaria por se tornar pior.

Notamos, assim, o movimento como importante agente no combate a todos esses males suscitados pelo envelhecimento: a dor, a doença, a falta de disposição, de pique, de ânimo. Mas, mais do que notar sua importante agência, é preciso atentar para o modo pelo qual este movimento atua. Podemos resgatar, então, todas aquelas sensaçóes que extrapolam o binarismo beleza-saúde e remetem a muitas formas de sentir - "sentir-se bem", "boa sensação", "disposição", "bom humor", "pique”, "sentir-se alegre", "sentir-se viva”, "estar mais desperta", "qualidade de vida" e "vitalidade" - e perceber como o movimento e o incentivado uso do corpo passam por tais sensações. Considerando o uso do corpo que se faz necessário, conforme colocado por Sérgio, e se faz sentido, como relataram Sandra e Vera, podemos pensar, a partir de Merleau-Ponty ([1945] 1996), em um corpo que não pode ser confundido com um objeto sobre o qual o sujeito elabora representações, mas visto como algo que está no mundo e que o experimenta:

Dizia-se ainda que o corpo é um objeto afetivo, enquanto as coisas exteriores me são apenas representadas. Isso era colocar uma terceira vez o problema do estatuto do corpo próprio. Pois, se digo que meu pé me incomoda, não quero dizer simplesmente que ele é uma causa de dor equivalente ao prego que o fere, e apenas mais próxima; não quero dizer que ele é o último objeto do mundo exterior, após o qual começaria uma dor do sentido íntimo, uma consciência de dor por si mesma sem lugar que só se ligaria ao pé por uma determinação causal e no sistema da experiência. Quero dizer que a dor indica seu lugar, que ela é constitutiva de um "espaço doloroso". "Tenho dor no pé" não significa: "Penso que meu pé é a causa dessa dor", mas: "a dor vem de meu pé" ou ainda "meu pé tem dor" (id., ibidem, p. 137-138, grifo nosso).

Essa reflexão de Merleau-Ponty nos conduz a um corpo que não está previamente delimitado e sobre o qual o sujeito tem apenas representaçóes a fazer. A dor constitui um "espaço doloroso" e torna-se por isso um modo de conhecer aquele espaço e de experimentá-lo. Em outras palavras, a dor possibilita uma experiência e um conhecimento específico do corpo.

O relato de Ana (47 anos, Academia Figueiredo) é importante para a percepção de que a dor tinha uma realidade fundamental tanto no contexto da academia como em experiências que lhe eram exteriores. Passado um tempo que eu havia finalizado esta pesquisa, encontrei Ana em uma biblioteca de Campinas, onde ela comentou que havia mudado de academia, deixando de frequentar a Academia Figueiredo, porque resolvera "mudar de ares". $\mathrm{O}$ treino da nova academia era bem mais "pesado" e Ana estava até sentindo dores no corpo, mas a dor que sentia era aquela "dor boa". Desse modo, "sentir o corpo" ou "sentir-se viva” era, de alguma forma, sentir aquela dor - uma dor que é "boa" quando pensamos em outras dores às quais ela está relacionada: doenças, mortes de familiares, maiores dificuldades em realizar exercícios que antes eram feitos sem as "dificuldades da velhice". Assim, podemos dizer que, ao mesmo tempo em que esta "dor boa" é relacional, ela nos evoca também outras formas de percepçôes corporais que a prática de exercícios físicos possibilitava a essas mulheres. Evoca, dessa maneira, outras 
formas de sentir o corpo e de ter consciência do mesmo.

Outro comentário de Sérgio também nos remete à importância da dor no exercício físico. Durante uma de suas aulas, ao explicar a forma de se fazer um exercício para glúteos, ele dizia às alunas que a sensaçáo a qual elas deveriam ter era a de uma dor no glúteo direito, como se fosse uma injeção. Sérgio insistia para que elas imaginassem uma injeção bem doída sendo aplicada. Apesar da acidez dessa imagem trazida pelo professor de ginástica, é inegável a importância da mesma, pois ela tornava mais clara tanto a dor como o espaço que ela constituía. A dor possibilitava uma percepção específica daquela parte do corpo. A sensação da dor durante a realização dos exercícios físicos era, de fato, inevitável. Mas, se trago sua presença para este texto, é principalmente porque, enquanto um modo de experimentar o corpo, a dor do exercício físico parecia ser sentida de maneiras distintas por mim e pelas mulheres com quem compartilhava aquelas aulas. $\mathrm{O}$ relato de Ana torna manifesta essa diferença, a qual foi de primeira importância para minha percepção de que as dores sentidas na realização do exercício corporal estavam relacionadas com outras dores que o envelhecimento trazia consigo, as quais eram tấo ressaltadas por aquelas mulheres. Para mim, o referido processo de envelhecimento não era tomado como um problema, eu não sentia seus efeitos. Assim, não via de maneira igualmente positiva a dor que sentia ao realizar exercícios físicos e não sentia do mesmo modo a necessidade de estar sempre em movimento.

A urgência do movimento do corpo estava, portanto, diretamente relacionada a um antimovimento que parecia se aproximar e o atingir. Podemos, assim, lembrar de Graça (52 anos, Academia Figueiredo) que adorava pular e, "mais do que ficar linda e maravilhosa", "sen- tir-se com agilidade" a partir da possibilidade de sair dançando. Ela viajava bastante para o Maranhão e via "as velhinhas de lá" dançando um tambor de crioula por quatro horas. Graça invejava aquelas mulheres e dizia que elas se limitavam muito menos que as do sul do país, onde a "mulher mais velha" passa a não fazer mais nada, não se diverte e não dança.

Desse modo, o trabalho corporal nas academias de ginástica possibilitava àquelas mulheres diferentes e inovadores modos de conhecer e vivenciar seus corpos, que nos remetem às novas formas de conhecer propostas por Dom Juan a Castaneda (1969), as quais passam pela experiência de sentir. Mais do que buscar um objetivo totalmente estabelecido entre a busca de um corpo belo e/ou saudável, a experiência nas academias de ginástica criava a possibilidade de transformação corporal, a qual percorria novos modos de o sentir e conhecer. Frente a um corpo que, durante o considerado processo de envelhecimento, via-se inevitavelmente cada vez mais ameaçado pelas dores, doenças e falta de agilidade, a possibilidade de movimentá-lo e de, por meio deste movimento, senti-lo de diferentes formas, aparece como uma radicalização no sentido contrário daquele inevitável sentido da idade.

\section{Pain in movement: body and aging in the} gym

abstract Based on an ethnographic research at fitness clubs, this article proposes a reflection upon the experiences of the body and of aging as felt by women who attend the gym. The interest of this work relies on the understanding and ethnographic perception of the way in which these women in their forties relate to the space of the gym and to the corporeal practices performed there by them. Pursuing a displacement of the subject conceived as unique 
and human, the article explores the possible existent relations between gender, body, aging, pain, disease and movement. The intent is to turn perceptible the pragmatic and relational character of the experience as lived by these women when exercising and equally to question the well established concepts of health, beauty and well-being.

key-words Gym. Body. Ecology. Aging. Experience.

\section{Notas}

1. A escolha dos 40 anos como marco, baseou-se na popularização da ideia de que acontece uma crise da meia-idade com a aproximação dos 40 anos (cf. Featherstone, 1998; Py \& Scharfstein, 2001).

2. Para uma análise mais detalhada a respeito das diferentes construçóes de categorias etárias, ver Debert (1998). A autora explora o tema da velhice e mostra como as formas pelas quais o envelhecimento é concebido e vivido variam de sociedade para sociedade, ocorrendo, portanto, modificaçôes na idade a partir da qual os indivíduos são considerados velhos, na posição social ocupada por eles e no tratamento que estes recebem dos jovens. Outros estudos vêm igualmente mostrando como o chamado processo de envelhecimento é socialmente constituído, em distintos contextos (cf. p. ex. Featherstone \& Wernick, 1995; Hareven, 1999; Coimbra Jr. \& Minayo, 2002; Debert, 1998, 2004).

3. Foram analisados folders e outros textos de propaganda elaborados pelas academias, além de documentos informativos sobre o cuidado com o corpo de maneira geral os quais eram divulgados por meio de murais nas academias.

4. Este artigo trata, portanto, de uma releitura desse material, a qual só se tornou possível a partir de reflexôes que tiveram origem em dois cursos que realizei: Mito e Ritual, ministrado pela professora Maria Suely Kofes no Departamento de Antropologia da Universidade Estadual de Campinas em 2008; e Epistemologia da Antropologia, ministrado pela professora Antonádia Monteiro Borges no Departamento de Antropologia da Universidade de Brasília em 2010. Outra experiência ainda foi fundamental para essa releitura: o fato de eu voltar a fazer exercícios em aulas de hidroginástica com mulheres "mais velhas" no ano de 2010.

5. Os nomes das pessoas envolvidas nesta pesquisa e citadas neste artigo foram modificados a fim de resguardar a privacidade das mesmas.

6. Podemos entender o chão, os pontos e as cores como entidades atuantes no processo de conhecimento de Castaneda, não ocupando simplesmente lugares de objetos passivos de observaçáo. Tal entendimento tem como base a consideração de um mundo social em que a diferença básica e estática entre sujeito atuante e objeto passivo não faz sentido. Neste momento, não será possível desenvolver essa discussão, mas cabe ressaltar que ela tem como ponto de partida os trabalhos de Bruno Latour (cf. principalmente Latour, 2005).

7. Ou dizer que, ao invés de mentirem, afirmavam uma motivação relacionada à saúde por esta ser uma fala politicamente correta, ligada a um motivo mais nobre.

8. Aqui, utilizo o verbo "dizer" náo querendo remeter apenas à dimensão estrita da "fala". Valho-me deste verbo de maneira mais ampliada, abarcando o que as mulheres me diziam não apenas por palavras, mas também por seus gestos e expressóes. De modo semelhante, muito do que pude perceber em meu trabalho de campo estava diretamente ligado à relação entre as sensaçóes que elas me narravam e o modo pelo qual eu percebia o impacto do exercício físico em meu próprio corpo.

9. Nas aulas de Sérgio, era possível notar a presença de alguns poucos homens, embora a maioria da turma fosse composta por mulheres com mais de 35 anos.

10. O step é um objeto utilizado em aulas de exercício aeróbico de mesmo nome. Trata-se de uma pequena plataforma que possibilita a realizaçáo de diversos movimentos que se valem do desnível em relação ao solo proporcionado por tal objeto.

11. Esta academia elaborou um folder através do qual eram divulgadas aulas consideradas inovadoras oferecidas pela mesma. O próprio nome das aulas buscava traduzir essa ideia de modernidade e inovaçáo. "Extreme 55" definia-se como "o mais moderno e revolucionário programa de treinamento de resistência localizada com halteres e step. São 55 minutos de extrema energia e intensidade numa aula ideal para a redução de gordura, tonificação e definição muscular para todo o corpo. EXTREME $55^{\circ}$ é sem dúvida o treinamento localizado que o Brasil necessitava!"; e "Power Mix" definia-se por ser "formado por três blocos de exercícios combinados em três séries, que 
visam um trabalho completo de todo o corpo com cargas progressivas, através da utilização de um conjunto de barras e anilhas. Um dos principais objetivos do POWER MIX ${ }^{\circledast}$ é oferecer aos praticantes, novas idéias de treinamento com barra, baseadas nas novas tendências do fitness mundial.".

12. Como recentes estudos inseridos no campo da antropologia das emoçốes vêm explicitando, "as experiências subjetivas" não deixam de estar "atreladas a gramáticas culturais” (Coelho \& Rezende, 2010, p. 126). Sensaçóes tais quais as de prazer, medo, felicidade são, antes de tudo, socialmente produzidas e vivenciadas (cf. Duarte, 1999; Rezende, 2002).

13. Neste artigo, analiso um modo específico de concepção e experimentação da dor, associado à prática de exercícios físicos e ao envelhecimento. Diversos outros estudos mostram como a sensação da dor pode ser percebida de diferentes modos a partir de contextos sociais e históricos particulares (cf. Le Breton, 1995; Guerci, 1998).

14. Para além da agência de doenças e dores, Sautchuk (2007) nos remete às formas de existência da gordura nas práticas corporais empreendidas nas academias de ginástica e o modo pelo qual a mesma integra as concepçóes de corpo e pessoa. A gordura aparece sob múltiplas formas - é um componente orgânico, um critério estético, um risco à saúde ou ataque à autoestima -, havendo procedimentos capazes de traduzi-la nos diferentes modos.

15. Maria, por exemplo, dizia que a prática de exercícios físicos ajudava a "abaixar e pegar as coisas" sem sentir dor. Antes de ir à academia, ela dançava (frequentava bailes todos os sábados e dançava por duas horas seguidas) e não tinha problemas; mas, quando parou de dançar, começou a sentir dores ao realizar exercícios cotidianos.

\section{Referências bibliográficas}

CASTANEDA, Carlos. The Teachings of Don Juan: A Yaqui Way of Knowledge. Berkeley: University of California Press, 1969.

CASTRO, Ana Lúcia de. Culto ao corpo e sociedade: mídia, estilos de vida e cultura de consumo. São Paulo: Annablume, 2003.

COIMBRA Jr., Carlos E. A \& MINAYO, Maria Cecília de Souza (Orgs.). Antropologia, Saúde e Envelhecimento. Rio de Janeiro: Editora Fiocruz, 2002.
COELHO, Maria Claudia \& REZENDE, Claudia Barcellos. Antropologia das emoçôes. Rio de Janeiro: Editora FGV, 2010.

DEBERT, Guita Grin. A reinvenção da velhice: socialização e processos de reprivatização do envelhecimento. São Paulo: Edusp/ Fapesp, 2004.

- Pressupostos da reflexão antropológica sobre a velhice. In: (Org.). Antropologia e Velhice. Campinas: IFCH/Unicamp, 1998. p. 7-27.

DUARTE, Luiz Fernando Dias. O império dos sentidos: sensibilidade, sensualidade e sexualidade na cultura ocidental moderna. In: HEILBORN, Maria Luiza (Org.). Sexualidade: o olhar das ciências sociais. Rio de Janeiro: Jorge Zahar, 1999. p. 21-30.

ELIAS, Norbert. A solidão dos moribundos, seguido de, Envelhecer e morrer. Rio de Janeiro: Jorge Zahar Ed., 2001.

FEATHERSTONE, Mike. O curso da vida: corpo, cultura e o imaginário no processo de envelhecimento. In: DEBERT, Guita Grin (Org.). Antropologia e Velhice. Campinas: IFCH/Unicamp, 1988. p 49-71.

FEATHERSTONE, Mike \& WERNICK; Andrew (Org.). Images of Aging: Cultural Representations of Later Life. Londres: Routledge, 1995.

FERNANDES, Rita de Cássia. Significados da ginástica para mulheres praticantes em academia: corpo, saúde e envelhecimento. Dissertação (Mestrado) - Faculdade de Educação Física, Universidade Estadual de Campinas, Campinas, 2004.

FOUCAULT, Michel. História da sexualidade I: a vontade de saber. Rio de Janeiro: Ediçôes Graal, [1976] 1988.

FRAGA, Alex Branco \& SOARES, Carmen Lúcia. Pedagogia dos corpos retos: das morfologias disformes às carnes humanas alinhadas. Pro-posiçôes, Campinas, v. 14, n. 2, p. 77-90, maio/agosto 2003.

FRUGOLI, Rosa. Academia de ginástica: contemporaneidade, expressões corporais e sentido. In: Congresso Luso-Afro-Brasileiro de Ciências Sociais, 7., 2004, Coimbra. Anais eletrônicos.... Coimbra: Universidade de Coimbra, 2004. Disponível em: <http://www.ces. uc.pt/lab2004/pdfs/RosaFrugoli.pdf>. Acesso em: 31 jan. 2007.

GOLDENBERG, Mirian. Apresentação. In: (Org.). Nu \& Vestido: dez antropólogos revelam a cultura do corpo carioca. Rio de Janeiro: Record, 2002. p. 7-17.

GUERCI, Antonio. An anthropological approach to pain. Revista de la Sociedad Espanola del Dolor, Tenerife, v. 5, supl. 1, p. 19-27, 1998.

HARAWAY, Donna Jeanne. Manifesto ciborgue: ciência, tecnologia e feminismo-socialista no final do século 
XX. Tradução de Tomaz Tadeu da Silva. In: SILVA, Tomaz Tadeu da. Antropologia do ciborgue: as vertigens do pós-humano. Belo Horizonte: Autêntica, 2000. p. 37-129.

HAREVEN, Tamara K. Novas imagens do envelhecimento e a construção social do Curso da Vida. Cadernos Pagu, Campinas, v. 13, p. 11-35, 1999.

LATOUR, Bruno. Reassembling the Social: an Introduction to Actor-Network-Theory. Nova York: Oxford University Press, 2005.

LE BRETON, David. Anthropologie de la douleur. Paris: Métailié, 1995.

MALINOWSKI, Bronislaw. Baloma: Os espíritos dos mortos nas Ilhas Trobriand. In . Magia, Ciência e Religião. Lisboa: Ediçóes 70, [1916] 1988. p. 155-272.

MALYSSE, Stéphane. Em busca de (H)alteres-ego: Olhares franceses nos bastidores da corpolatria carioca. In: GOLDENBERG, Mirian (Org.). $N u$ \& Vestido: dez antropólogos revelam a cultura do corpo carioca. Rio de Janeiro: Record, 2002. p. 79-137.

MERLEAU-PONTY, Maurice. Fenomenologia da percepção. São Paulo: Martins Fontes, [1945] 1996.

MIRA, Maria Celeste. Da higiene à musculação: esboço para um estudo das mudanças nas concepções e práticas corporais através da história da educação física. ENCONTRO ANUAL DA ANPOCS, 28², 2004, Caxambu. Mimeo. Caxambu: Hotel Glória, 2004.

PEIRANO, Mariza G. S. A análise antropológica de rituais. In: . (Org.). O dito e o feito: ensaios de antropologia dos rituais. Rio de Janeiro: Remule Dumará, 2002. p.17-40.

PIGNARRE, Philippe \& STENGERS, Isabelle. La sorcellerie capitaliste: pratiques de désenvồtement. Paris: Editions La Découverte, [2005] 2007.
PY, Ligia \& SCHARFSTEIN, Eloisa Adler. Caminhos da maturidade: representaçôes do corpo, vivências dos afetos e consciência da finitude. In: NERI, Anita Liberalesso (Org.). Maturidade e velhice: trajetórias individuais e socioculturais. Campinas: Papirus, 2001. p. 117-150.

REZENDE, Claudia Barcellos. Mágoas de amizade: um ensaio em antropologia das emoçóes. Mana, Rio de Janeiro, v. 8, n. 2, p. 69-89, 2002.

ROSE, Nikolas. The Politics of Life Itself. Theory, Culture \& Society, Sage Publications, v. 18, n. 6, p. 1-30, 2001.

SANT'ANNA, Denise Bernuzzi de. Transformações do corpo: controle de si e uso dos prazeres. In: RAGO, Margareth; ORLANDI, Luiz B. Lacerda \& VEIGA-NETO, Alfredo (Org.). Imagens de Foucault e Deleuze: ressonâncias nietzschianas. Rio de Janeiro: DP\&A, 2002. p. 99-110.

SASSATELLI, Roberta. Interaction Order and Beyond: A Field Analysis of Body Culture within Fitness Gyms. Body and Society, Londres, v. 5, n. 2-3, p. 227-248, 1999.

. Fitness Culture: Gyms and the Commercialisation of Discipline and Fun. Houndsmills: Palgrave Macmillan, 2010.

SAUTCHUK, Carlos Emanuel. A medida da gordura: o interno e o íntimo na academia de ginástica. Mana, Rio de Janeiro, v. 13, n. 1, p. 181-205, 2007.

STENGERS, Isabelle. Experimenting with refrains: subjectivity and the challenge of escaping modern dualism. Subjectivity, Palgrave Macmillan, v. 22, p. 38-59, 2008.

VAZ, Alexandre Fernandez. Corpo, educação e indústria cultural na sociedade contemporânea: notas para reflexão. Pro-posições, Campinas, v. 14, n. 2, maio/ agosto 2003.

VIVEIROS DE CASTRO, Eduardo. O Nativo Relativo. Mana, Rio de Janeiro, v. 8, n. 1, p. 113-148, 2002.

\author{
autora Aline Alcarde Balestra \\ Mestranda em Antropologia Social / UnB
}

Recebido em 27/03/2012

Aprovado para publicação em 01/10/2012 